\title{
Erratum: Reversible Kallmann syndrome: report of the first case with a KAL1 mutation and literature review
}

Rogerio Silicani Ribeiro, Teresa Cristina Vieira and Julio Abucham

Neuroendocrine Unit, Division of Endocrinology, Department of Medicine, Escola Paulista de Medicina, Universidade Federal de São Paulo, Rua Pedro de Toledo 910, 04039002 São Paulo, Brazil

(Correspondence should be addressed to J Abucham; Email: julioabucham@uol.com.br)

The authors and journal apologize for an error in the above paper which appeared in 156 (3) 285-290. In this paper, on pages 285 and 287, the length of the wild-type KAL1 gene product anosmin 1 was incorrectly given as 610 amino acids. The correct length of the protein is 680 amino acids.

European Journal of Endocrinology 156703 